Fixed Point Theory, 22(2021), No. 1, 251-262

DOI: $10.24193 /$ fpt-ro.2021.1.18

http://www.math.ubbcluj.ro/ nodeacj/sfptcj.html

\title{
AN EXTENSION OF THE POINCARÉ-BIRKHOFF FIXED POINT THEOREM TO NONINVARIANT ANNULI
}

\author{
ALEXANDER KIRILLOV \\ Institute of Applied Mathematical Research, Karelian Research Centre, \\ Russian Academy of Sciences, \\ 11, Pushkinskaya str., Petrozavodsk Karelia 185910, Russia \\ E-mail: krllv1812@yandex.ru
}

Abstract. An extension of the Poincaré-Birkhoff fixed point theorem to noninvariant under areapreserving homeomorphism annuli is considered. Unlike the well-known W.-Y. Ding's theorem [7], the inner boundary component of an annulus is not assumed to be star-shaped, while the outer boundary component is star-shaped. The existence of at least two fixed points for area preserving homeomorphism satisfying some twist condition is proved.

Key Words and Phrases: Poincaré-Birkhoff fixed point theorem, noninvariant annulus, non-starshaped boundary.

2020 Mathematics Subject Classification: 54H25, 37E40, 47H10.

Acknowledgment. The author would like to thank V.V. Starkov for some useful comments. The author has been supported by RFBR (18-01-00249a).

\section{REFERENCES}

[1] G.D. Birkhoff, Proof of Poincaré's geometric theorem, Trans. Amer. Math. Soc., 14(1913), $14-22$.

[2] G.D. Birkhoff, An extension of Poincare's last geometric theorem, Acta Math., 47(1925), 297311.

[3] M. Brown, W.D. Neumann, Proof of the Poincaré-Birkhoff fixed point theorem, Michigan Math. J., 24(1977), 21-31.

[4] P.H. Carter, An iprovement of the Poincaré-Birkhoff fixed point theorem, Trans. Amer. Math. Soc., 269(1982), 285-299.

[5] F. Dalbono, C. Rebelo, Poincaré-Birkhoff fixed point theorem and periodic solutions of asymptotically linear planar hamiltonian system, Rend. Sem. Mat. Univ. Pol. Torino, 60(2002), 233263.

[6] T. Ding, Approaches to the Qualitative Theory of Ordinary Differential Equations, Peking University Series in Mathematics, 3, World Scientific, 2007.

[7] W.-Y. Ding, A generalization of the Poincaré-Birkhoff theorem, Proc. Amer. Math. Soc., 88(1983), 341-346.

[8] A. Fonda, M. Sabatini, F. Zanolin, Periodic solutions of perturbed hamiltonian systems in the plane by the use of Poincaré-Birkhoff theorem, Topological Meth. Nonlinear Anal., 40(2012), $29-52$. 
[9] J. Franks, Generalizations of the Poincaré-Birkhoff theorem, Ann. of Math., 128(1988), 139151.

[10] L. Guillou, A simple proof of P. Carter's theorem, Proc. Amer. Math. Soc., 125(1997), 15551559.

[11] H. Jacobowitz, Periodic solutions of $x^{\prime \prime}+f(t, x)=0$ via the Poincaré-Birkhoff theorem, J. Differential Equations, 20(1976), 37-52.

[12] B. Kerékjarto, The plain translation theorem of Brouwer and the last geometric theorem of Poincaré, Acta Sci. Math. (Szeged), 4(1928), 86-102.

[13] A. Kirillov, V. Starkov, Some extensions of the Poincaré-Birkhoff theorem, J. Fixed Point Theory Appl., 13(2013), 611-625.

[14] A. Kirillov, V. Starkov, Fixed points of infinitely connected domain continuous mappings, Fixed Point Theory, 16, (2015), 103-106.

[15] P. Le Calvez, J. Wang, Some remarks on the Poincaré-Birkhoff theorem, Proc. Amer. Math. Soc., 138(2010), 703-715.

[16] Li Yong, Lin Zhenghua, A constructive proof of the Poincaré-Birkhoff theorem, Trans. Amer. Math. Soc., 347(1995), 2111-2126.

[17] A. Margheri, C. Rebelo, F. Zanolin, Maslov index, Poincaré-Birkhoff theorem and periodic solutions of asymptotically linear planar Hamiltonian systems, J. Differ. Equ., 183(2002), 342367.

[18] R. Martins, A.J. Urena, The star-shaped conditionon on Ding's version of the Poincaré-Birkhoff theorem, Bull. London Math. Soc., 39(2007), 803-810.

[19] J.C. Oxtoby, S.M. Ulam, Measure preserving homeomorphisms and metrical transitivity, Ann. of Math., 42(1941), no. 2, 874-920.

[20] A. Pascoletti, F. Zanolin, A topological approach to bend-twist maps with applications, Int. J. Differ. Equ., 2011(2011) 20 p.

[21] H. Poincaré, Sur un théeorème de géomètrie, Rendiconti del Circolo Mat. Palermo, 33(1912), 375-507.

[22] C. Rebelo, A note on the Poincaré-Birkhoff fixed point theorem and periodic solutions of planar systems, Nonlinear Analysis - Theory, Methods and Applications, 29(1997), 291-311.

[23] H.E. Winkelnkemper, A generalization of the Poincaré-Birkhoff theorem, Proc. Amer. Math. Soc., 102(1988), 1028-1030.

Received: April 14, 2018; Accepted: January 17, 2019. 